\title{
Parental origin of deletions and duplications - about the necessity to check for cryptic inversions
}

Thomas Liehr $^{1 *}$ (D), Isolde Schreyer ${ }^{1,2}$, Alma Kuechler ${ }^{3}$, Emmanouil Manolakos $^{4}$, Sylke Singer ${ }^{5}$, Andreas Dufke ${ }^{5}$, Kathleen Wilhelm¹, Tereza Jančušková ${ }^{6}$, Radek Čmejla ${ }^{6}$, Moneeb A. K. Othman', Ahmed H. Al-Rikabi', Kristin Mrasek', Monika Ziegler', Stefanie Kankel ${ }^{1}$, Katharina Kreskowski ${ }^{1}$ and Anja Weise ${ }^{1}$

\begin{abstract}
Background: Copy number variants (CNVs) are the genetic bases for microdeletion/ microduplication syndromes (MMSs). Couples with an affected child and desire to have further children are routinely tested for a potential parental origin of a specific CNV either by molecular karyotyping or by two color fluorescence in situ hybridization (FISH), yet. In the latter case a critical region probe (CRP) is combined with a control probe for identification of the chromosome in question. However, CNVs can arise also due to other reasons, like a recombination-event based on a submicroscopic, cryptic inversion in one of the parents.

Results: Seventy-four patients with different MMSs and overall 81 CNVs were studied here by a novel three color FISH approach. The way how three locus-specific probes are selected (one is the CRP and two are flanking it in a distance of 5-10 Mb) enables to detect or exclude two possible parental conditions as origins of the CNV seen in the index: (i) direct parental origin of the CNV (deletion or duplication) or (ii) a parental cryptic inversion. Thus, for overall 51/81 CNVs (63\%) a parental origin could be determined. 36/51 (70.5\%) inherited the CNV directly from one of the parents, but 15/51 (29.5\%) were due to an exclusively by three color FISH detectable parental inversion. A 2:1 ratio of maternal versus paternal inheritance was found. Also almost two times more male than female were among the index patients.

Conclusion: The new, here suggested three color FISH approach is suited for more comprehensive parental studies of patients with MMS. The detection rate for parental origin was increased by 140\% in this study. Still, for 30/81 cases (37\%) no reason for the 'de novo' MMS in the affected index patient could be found by the here suggested FISH-probe set.
\end{abstract}

Keywords: Copy number variants (CNVs), Microdeletion/microduplication syndromes (MMSs), Three color fluorescence in situ hybridization (FISH), Inversion, Deletion, Duplication

\section{Background}

Copy number variants (CNVs) are a topic of highest interest in research and diagnostics [1]. Gain or loss of submicroscopic regions can either lead to clinical signs and symptoms $[1,2]$, suspected to be associated with diseases [1-3] or, according to present knowledge, just be variations without any significant meaning for the individual carrier $[1,4]$.

\footnotetext{
* Correspondence: Thomas.Liehr@med.uni-jena.de

${ }^{1}$ Jena University Hospital, Institute of Human Genetics, Friedrich Schiller

University, Postfach D-07740, Jena, Germany

Full list of author information is available at the end of the article
}

However, the way how CNVs change their size if they are passed from one generation to the next, i.e. how specific DNA-regions are lost or amplified within a $\mathrm{CNV}$, is not completely understood, yet. Unequal crossing over events in low copy repeat regions $[1,5,6]$, or complicated repair mechanisms after DNA-break and/or replication stress, like non allelic homologous recombination (NAHR), microhomology-mediated break-induced replication (MMBIR), or even chromothripsis are discussed $[1,6-8]$. Another idea for CNV-formation related to MMBIR is based on the fact that regions involved in microdeletion/microduplication syndromes (MMSs) [2] can be 
flanked by repetitive elements being identical to each other, as first described by Jim Lupskis group for a $\sim 1.4 \mathrm{Mb}$ region in $17 \mathrm{p} 12$ including the PMP22 gene [9]. Such a genetic environment may cause unequal crossing over during meiosis (or even mitosis [10,11]), and thus deletion or duplication; i.e. a de novo CNV may arise in gametes or somatic cells. Recently, evidence was provided that at least in a subset of MMSs their corresponding critical regions (CRs) are flanked by DNA-stretches with sequence identity of 10-200 kb in size [12]. Besides, it has been shown that these CRs can be 'inverted' in one of the parents of a patient (e.g. [13, 14]), making a deletion or duplication more likely due to inversion loop formation [15]. Surprisingly, fathers or mothers of an MMS-patient may also be carrier of the identical deletion or duplication as the index patient, but without showing any, or only minimal symptoms of the corresponding syndrome [2]. This has been explained by the so-called two-hit model, suggesting a second large $\mathrm{CNV}$ only present in the patient and not in the parent $[12,16]$, or by a disease causing mutation in the not-deleted, corresponding relevant gene copy [17].

Here we analyzed parents of 74 index patients with different MMSs. A novel molecular cytogenetic approach was applied to detect or exclude two possible parental conditions as origins of the disease, as seen in the index: (i) direct parental origin of the CNV (deletion or duplication) or (ii) a parental cryptic inversion. Therefore we applied one locus-specific probe directly from the affected region (critical region probe $=\mathrm{CRP}$ ) and flanked it with two probes, located between 5 and $10 \mathrm{Mb}$ proximal and distal to the CRP. The analysis was done using a three color-fluorescence in situ hybridization (FISH) approach (Fig. 1). As 74 families and $81 \mathrm{CNVs}$ were studied overall (Table 1 and Additional file 1: Table S1), a first approximation could be achieved on the frequencies of parental origin versus 'de novo' formation of an MMS. However, cases considered as formed 'de novo' still may be due to NAHRs or inversions, which are too small to be detected by the here suggested FISH-probe set, like listed [4] and discussed elsewhere [18, 19].

\section{Methods}

\section{Samples}

Parents of 74 index patients as summarized in Table 1 and Additional file 1: Table S1 were studied. All index patients suffered from developmental delay and or/dysmorphic features, and each of them had one up to two microdeletions and/or microduplications (Table 1 and Additional file 1: Table S1), as characterized by molecular karyotyping and/or standard GTG-banding

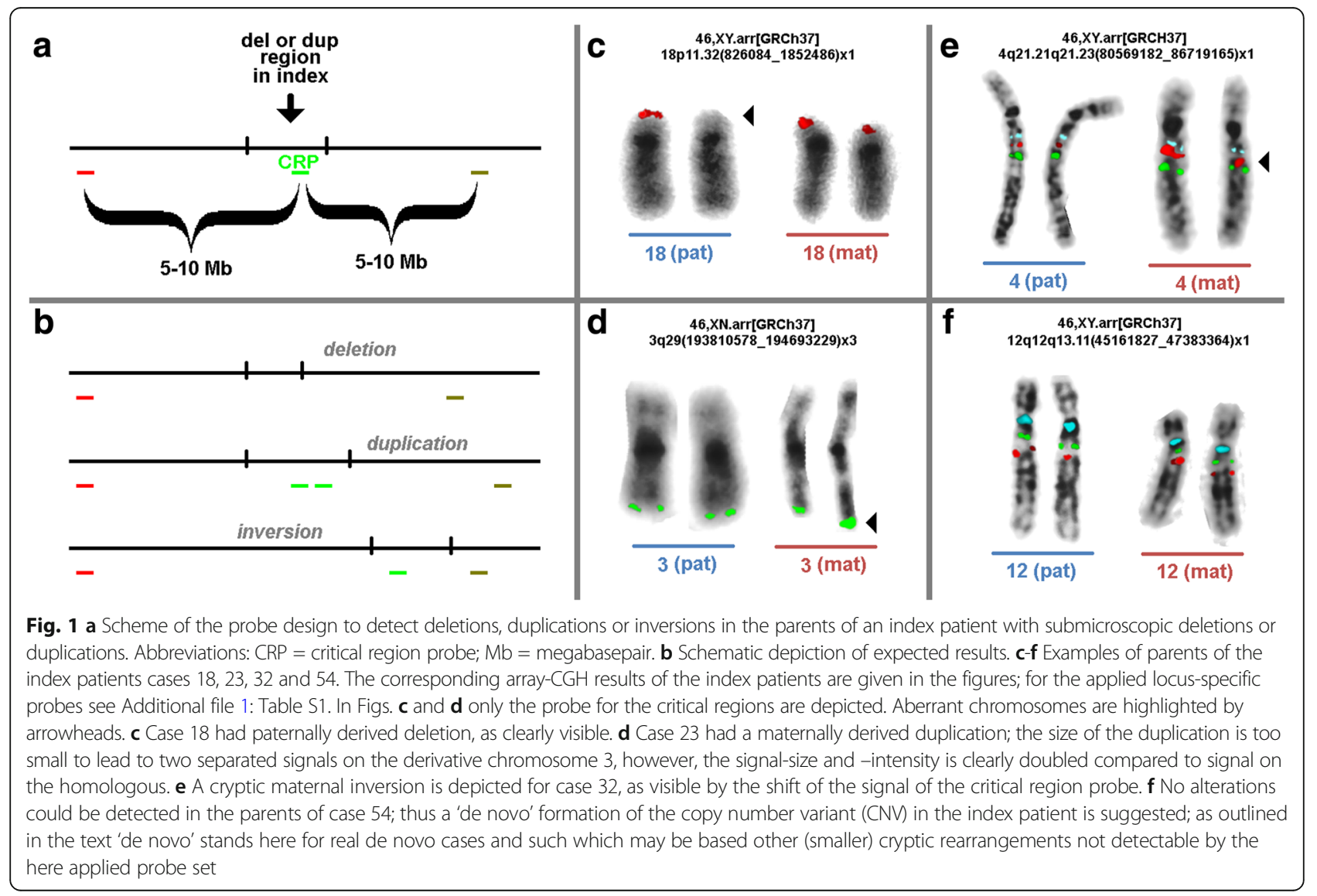


Table 1 Seventy-four families with affected children having deletion or duplication in one or two chromosomal regions included in this study are listed here. Overall 81 copy number variations (CNVs) distributed on all human chromosomes apart from \#11 and Y-chromosome were studied. Cases with two CNVs were numbered as A and B, i.e. cases 11, 13, 14, 17, 19 and 46. For the index patient the chromosomal region affected, the mode of inheritance of the CNV (origin) and the gender are given here; for more details see Additional file 1: Table S1

\begin{tabular}{|c|c|c|c|c|c|c|c|}
\hline $\begin{array}{l}\text { Case } \\
\text { number }\end{array}$ & $\begin{array}{l}\text { Chromosomal } \\
\text { region affected }\end{array}$ & Origin & $\begin{array}{l}\text { Gender } \\
\text { carrier }\end{array}$ & $\begin{array}{l}\text { Case } \\
\text { number }\end{array}$ & $\begin{array}{l}\text { Chromosomal } \\
\text { region affected }\end{array}$ & Origin & $\begin{array}{l}\text { Gender } \\
\text { carrier }\end{array}$ \\
\hline 1 & $2 \mathrm{q} 21.1 \mathrm{q} 21.3$ & del(mat/pat)cons. & n.a. & 37 & 7p12.3p14.1 & inv(mat) & $m$ \\
\hline 2 & $12 q 15 q 21.2$ & del(mat) & f & 38 & $4 q 13.3 q 22.1$ & inv(mat) & f \\
\hline 3 & $15 q 11.2$ & del(mat) & $f$ & 39 & $16 p 11.2$ & inv(mat) & $f$ \\
\hline 4 & $6 q 14.3 q 15$ & del(mat) & f & 40 & $17 q 21.31 q 21.31$ & $\operatorname{inv}(m a t) m o s$ & n.a. \\
\hline 5 & $6 q 22.33$ & del(mat) & m & 41 & $2 q 23.1 q 23.2$ & $\operatorname{inv}($ mat)mos & m \\
\hline 6 & Xp22.33 & del(mat) & m & 42 & 7q32.3q33 & inv(pat) & n.a. \\
\hline 7 & 12p12.3p12.3 & del(mat) & m & 43 & 7q31.32q32.2 & inv(pat) & m \\
\hline $8 a$ & $4 q 13.2 q 21.21$ & del(mat) & m & 44 & $6 q 21 q 22.31$ & inv(pat) & m \\
\hline 9 & $16 \mathrm{p} 11.2$ & del(mat) & $\mathrm{m}$ & 45 & $15 q 26.1 q 26.3$ & inv(pat) & m \\
\hline 10 & $2 p 16.3$ & del(mat) & $f$ & $46 a$ & $2 \mathrm{p} 14$ & inv(pat) & m \\
\hline $11 a$ & $16 p 13.11$ & del(mat) & n.a. & 47 & $15 q 13.2-q 13.3$ & de novo & n.a. \\
\hline $11 b$ & $16 p 13.11$ & del(mat) & n.a. & 48 & $8 q 24.3 q 24.3$ & de novo & n.a. \\
\hline 12 & $1 q 43 q 44$ & del(mat) & n.a. & 49 & 19p13.2p13.3 & de novo & m \\
\hline $13 a$ & $16 \mathrm{p} 12.2$ & del(mat) & m & 50 & 1p32.1p31.1 & de novo & $f$ \\
\hline $14 a$ & $14 q 12$ & del(mat)mos & n.a. & 51 & 7q31.1q31.1 & de novo & f \\
\hline $14 b$ & $15 q 11.2$ & del(mat)mos & n.a. & 52 & $14 q 12$ & de novo & n.a. \\
\hline 15 & $7 q 11.23 q 21.11$ & del(pat) & f & 53 & 16p11.2 & de novo & n.a. \\
\hline 16 & $1 \mathrm{q} 21.1$ & del(pat) & m & $19 b$ & $15 q 11.2 q 13.1$ & de novo & f \\
\hline $17 a$ & 16p13.11 & del(pat) & n.a. & 54 & $12 q 12 q 13.11$ & de novo & m \\
\hline $17 b$ & $16 \mathrm{p} 11.2$ & del(pat) & n.a. & 55 & $13 q 22.2 q 31.1$ & de novo & $f$ \\
\hline 18 & $18 p 11.32$ & del(pat) & m & 56 & $10 q 22.3 q 23.2$ & de novo & n.a. \\
\hline $19 a$ & $2 q 13$ & del(pat)mos & f & 57 & 7p15.3p15.2 & de novo & m \\
\hline 20 & $7 q 22.1$ & del(pat)mos & m & 58 & $6 q 13 q 15$ & de novo & n.a. \\
\hline 21 & $15 q 11.2$ & dup(mat) & n.a. & 59 & $4 q 21.22 q 22.1$ & de novo & f \\
\hline 22 & $5 q 11.1 q 11.2$ & dup(mat) & n.a. & 60 & $4 q 35.2$ & de novo & n.a. \\
\hline $8 b$ & $22 q 12.3 q 13.2$ & dup(mat) & m & 61 & $3 q 26.3 q 27.3$ & de novo & n.a. \\
\hline 23 & $3 q 29$ & dup(mat) & n.a. & 62 & $6 q 21 q 22.33$ & de novo & m \\
\hline 24 & $3 q 29$ & dup(mat) & n.a. & 63 & 3p14.1p12.3 & de novo & n.a. \\
\hline 25 & 19p13.3p13.3 & dup(mat) & $\mathrm{m}$ & 64 & $12 q 15 q 21.1$ & de novo & f \\
\hline 26 & $22 q 11.21$ & dup(mat)mos & m & 65 & $16 q 24.1 q 24.2$ & de novo & n.a. \\
\hline 27 & $7 q 34 q 36.3$ & dup(mat)mos & n.a. & 66 & 7p15.3 & de novo & n.a. \\
\hline 28 & $4 q 13.1$ & dup(pat) & n.a. & 67 & $9 q 22.31 q 22.33$ & de novo & n.a. \\
\hline 29 & 7q31.31q31.33 & dup(pat) & f & 68 & $16 q 24.1 q 24.3$ & de novo & n.a. \\
\hline 30 & $4 q 25$ & dup(pat) & n.a. & 69 & $2 q 31.1$ & de novo & n.a. \\
\hline 31 & $13 q 12.13$ & dup(pat) & n.a. & 70 & $21 q 22.12 q 22.2$ & de novo & n.a. \\
\hline $13 b$ & 8p23.1p22 & dup(pat) & m & 71 & $5 q 35.2 q 35.3$ & de novo & n.a. \\
\hline 32 & $4 q 21.21 q 21.23$ & inv(mat) & m & 72 & $4 q 21.1 q 21.21$ & de novo & n.a. \\
\hline 33 & 20p12.3 & inv(mat) & n.a. & 73 & $10 q 11.22 q 11.23$ & de novo & n.a. \\
\hline 34 & 1p36.13p16.11 & inv(mat) & n.a. & $46 \mathrm{~b}$ & $2 q 31.2 q 31.3$ & de novo & m \\
\hline 35 & $17 q 12$ & inv(mat) & m & 74 & $7 q 32.3 q 33$ & de novo & n.a. \\
\hline 36 & $17 q 21.31 q 21.31$ & inv(mat) & $\mathrm{m}$ & & & & \\
\hline
\end{tabular}


elsewhere. Parents were clinically and cytogenetically normal. Chromosomes were prepared from cultured peripheral T-lymphocytes according to standard procedures [20]. Slides for metaphases FISH (see below) were produced following the air-drying protocol [21].

\section{Molecular cytogenetics}

FISH was done according to standard procedures in a three color-FISH variant [22]. To straightforwardly identify the chromosomes of interest a corresponding whole chromosome painting or centromeric probe may be added in a fourth color. The principle scheme how the three color-FISH probe sets were constructed is shown in Fig. 1a. The expected results in case of deletion, duplication and inversion are depicted in Fig. 1b. Bacterial artificial chromosome (BAC) probes serving as CRP should not include regions of known CNVs, like e.g. used in studies detecting parental origin of chromosomes by FISH [23].

The probes as applied for each case are listed in Additional file 1: Table S1. Locus-specific BAC-probes were commercially available from BACPAC Resources Program (bacpac.chori.org) or available to the authors (via Synlab, Czech Republic). Probe labelling was done as previously reported [24]. Ten to Twenty metaphases were analyzed per case. Typical examples for FISH results are depicted in Fig. 1b-f.

\section{Results}

In this study the parental origin of $81 \mathrm{CNVs}$ in 74 index patients was determined by a new three-color FISH approach (Fig. 1a and b). Therefore, one locus-specific probe mapped to the in the index patient affected region (critical region probe $=\mathrm{CRP}$ ) was flanked by two probes, located between 5 and $10 \mathrm{Mb}$ proximal and distal to the CRP. It could be convincingly shown that such kind of probe set enables simultaneous detection of deletions (Fig. 1c) or duplications (Fig. 1d), as well as cryptic, and in GTG-banding submicroscopic, parental inversions (Fig. 1e); the latter are visible as altered distances of the three probes to each other in the affected chromosome. Overall, the parental origin of potentially disease causing CNVs could be determined in 51 of 81 of the studied cases $(63 \%$ - see Fig. 2). Also, there remained $37 \%$ of non-informative, here denominated as 'de novo' cases (Figs. 1f and 2).

Among the parentally derived cases there was one (case 1) with partial nullisomy $2 \mathrm{q} 21.1$ to $2 \mathrm{q} 21.3$ in the index patient. This was most likely due to consanguinity of the parents and heterozygosity of both for this CNV. The remainder $50 \mathrm{CNVs}$ could be clearly attributed to be of maternal $(33 / 50$ cases $=66 \%)$ or paternal inheritance $(17 / 50$ cases $=34 \%$ - see Fig. 2$)$. The obtained data is broken down more specifically in Fig. 3 for parental

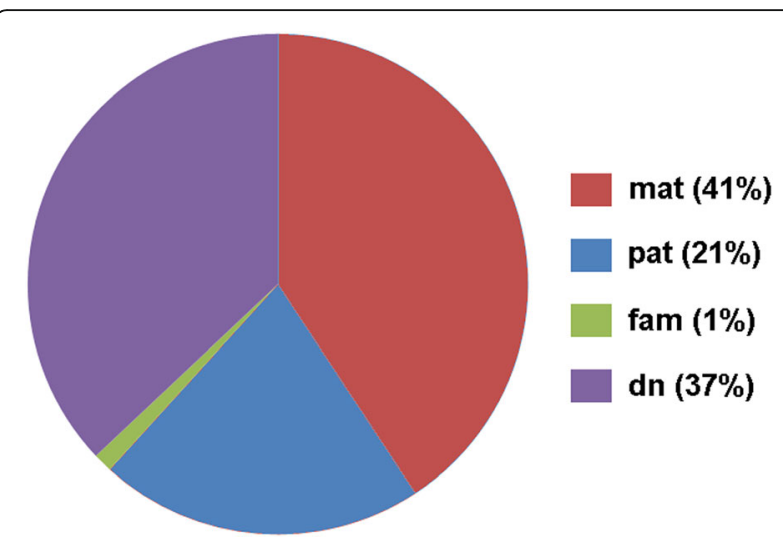

Fig. 2 Parental origin of the 81 here studied copy number variants (CNVs). Abbreviations: $d n=$ de novo; fam = familial; mat $=$ maternal; pat $=$ paternal

deletions, duplications or inversions. As shown in Table 1, four cases with deletion, and two cases each with duplication and inversion were mosaic in the transmitting parent.

The gender of the index patient was only available in 32 of the 74 cases. Thus, it could be evaluated for 43 $\mathrm{CNVs}$ studied here. Interestingly, overall the male to female ratio of the index was 28 to 15 ; considering only 'de novo' cases the ratio was $1: 1$, and in inherited cases the ratio was 1.8 to 1 (Fig. 4).

An analysis for the chromosomal origin of the CNVs (Fig. 5) revealed that they derived from practically all chromosomes. 15/81 CNVs were due to parental inversions (18.5\%) and those were detected on 6/24 chromosomes (25\%). However, 3/11 CNVs studied for chromosome 7, and $3 / 3 \mathrm{CNVs}$ studied for chromosome 17 were due to parental inversions. Finally, CNVs resulting from detectable parental inversions were between 545,601 bp (case 39) and $17,223,229$ bp (case 38) in size. As the corresponding inversions may provide just only one of their breakpoints to the resulting $\mathrm{CNV}$, the underlying inversions may have been larger or smaller.

\section{Discussion}

CNVs may arise by different mechanisms as outlined above [1]. To provide information for affected families about the repetition risk in a following pregnancy, yet the only routinely offered studies for a possible parental origin of a CNV are either molecular karyotyping [25] or two-color-FISH using one CRP and one control probe; the latter is applied to identify the chromosome of interest [10]. Thus, yet only parentally derived deletions or duplications may be detected, but no structural changes. Even though single studies showed that it is necessary in MMS like Angelman/Prader-Willi [13] Williams-Beuren [14] and Sprintzen velocardiofacial syndrome [26] also to check for potentially, in the offspring disease causing 


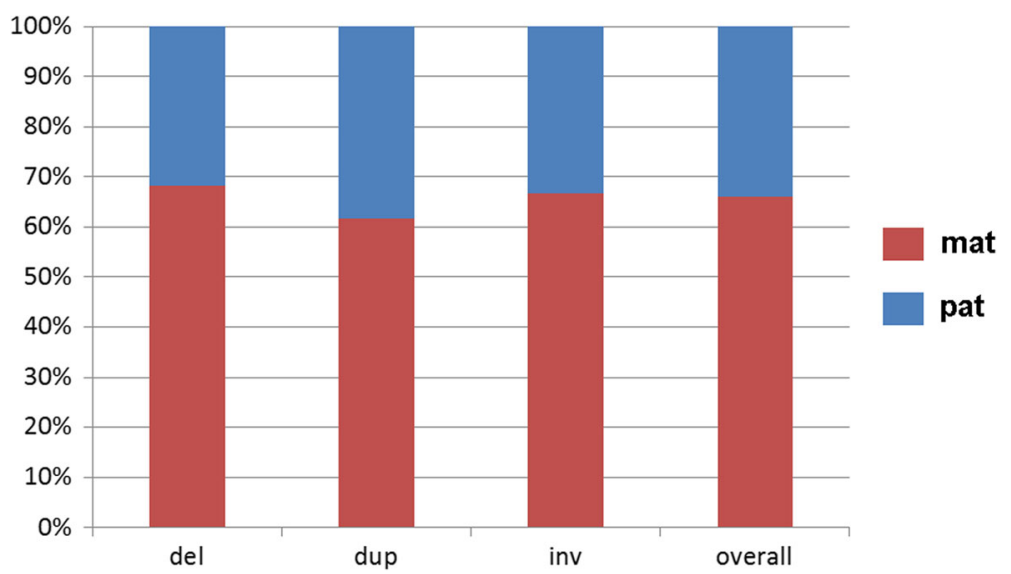

Fig. 3 Parental derived CNVs of cases 2 to $46 a$ were analyzed here for their maternal and paternal origin; 62 to $68 \%$ of the cases were maternally derived. Interestingly, in 8 cases mosaics of normal cells and cells with either maternal or paternal deletion, maternal duplication or maternal inversion were detected in the peripheral blood the tested parents (see Additional file 1: Table S1). Abbreviations: del = deletion; dup = duplication; inv. = inversion; mat $=$ maternal; pat $=$ paternal

inversions, no systematic studies in other MMSs were undertaken, yet. This gap was closed by the present study using a simple three-color-FISH probe set, as suggested here in Fig. 1a, which may be applied in each individual MMS case, as long as a CRP and flanking probes are available.

Thus, the detection rate of a proven parental origin for an MMS can be drastically enhanced. Traditionally, only using FISH with a CRP and a control probe or molecular karyotyping, parental origin of the deletion or duplication would have been solved in the present cohort for only 36/81 CNVs (44\%). With the new, here presented approach 15 additional CNVs could be attributed to a parental origin (i.e. an inversion) raising the detection rate up to $63 \%$. The remainder 30 cases, denominated here as 'de novo', could not be resolved with this probe set. They still may be due to NAHR, i.e. processes during gametogenesis like observed in Charcot-MarieTooth disease type 1A (CMT1A) [9, 10], or also be based on smaller inversions not detectable by this kind of metaphase-FISH directed probe set, but rather by interphase-FISH [14]. Interestingly, for all three groups (deletion, duplication and inversion) examples were found, which were present only in mosaic state in the transmitting parent. This suggests most likely a postzygotic origin of the rearrangement in the parent; still, also reversion could be considered. Cases like that are already reported e.g. for CMT1A and have been shown to go together with a less severe symptomatic [10], which goes together well with the fact that all parents in this study were considered as asymptomatic. Furthermore, mosaic conditions are known to be variable in

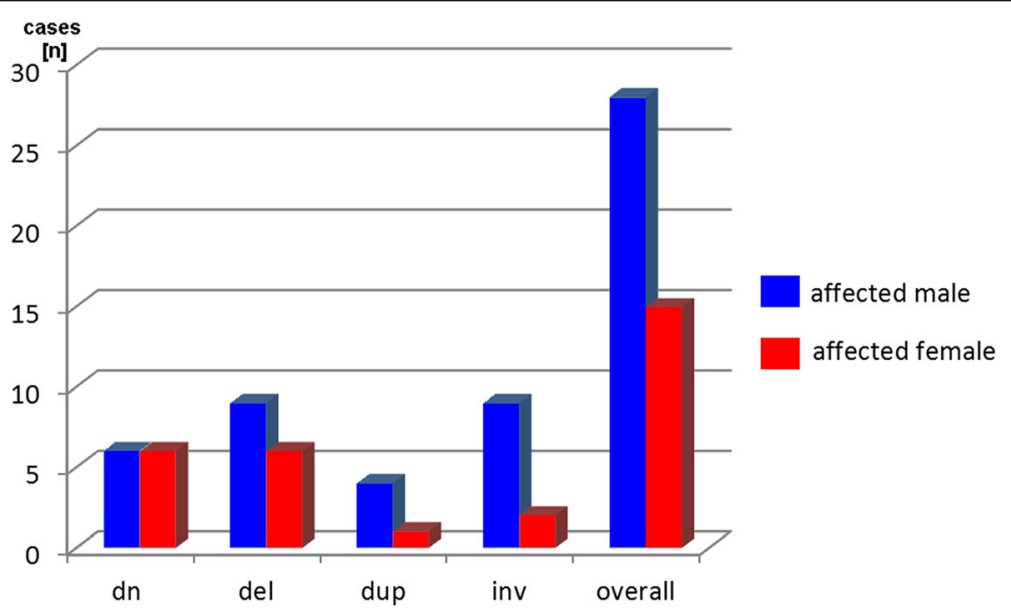

Fig. 4 In 43 cases the gender of the affected index patient was available. Interestingly, overall more male than female were affected, if the CNV was inherited from one of the parents. Abbreviations: $\mathrm{dn}=$ de novo; del = deletion; dup = duplication; inv. = inversion 


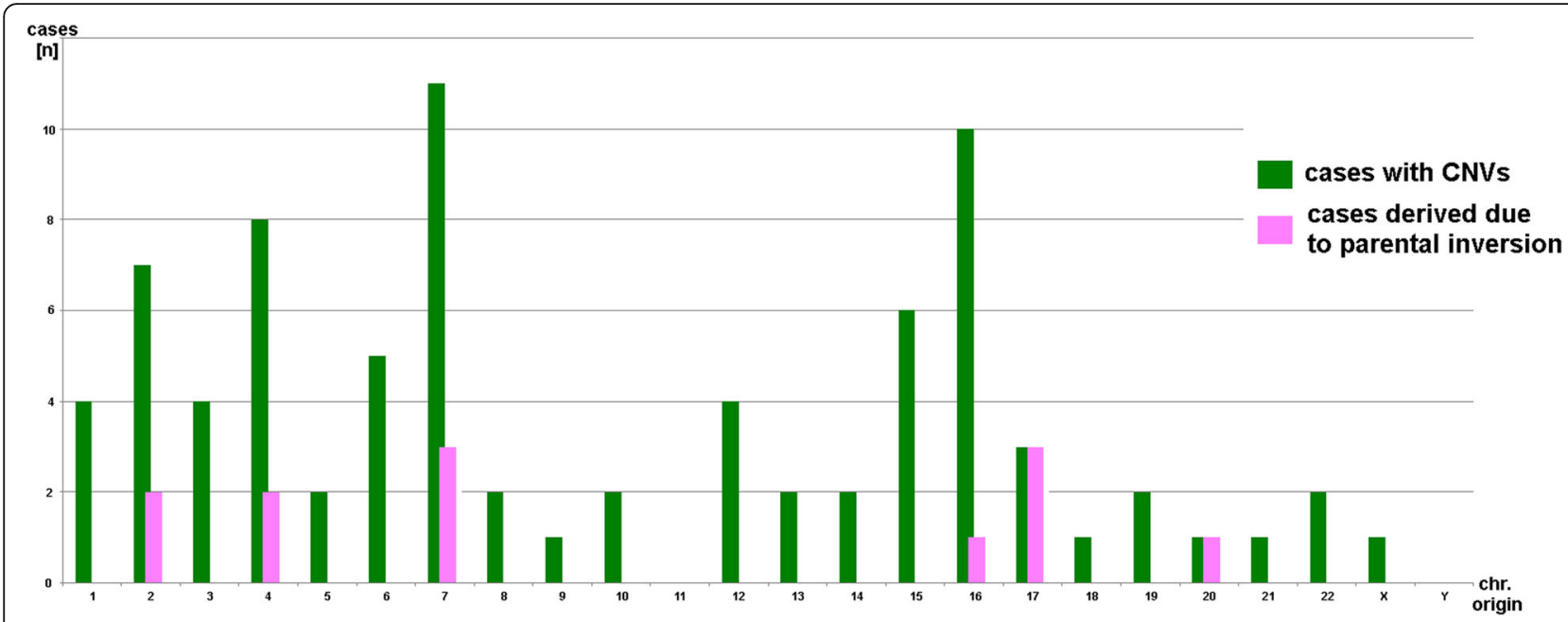

Fig. 5 The 81 here studied copy number variants (CNVs) sotted according to their chromosomal origin; cases which are due to a parental submicroscopic inversion are highlighted in pink. Abbreviations: CNVs = copy number variants

different tissues of the body [27]; thus, for all parental tests presently available it has always to be considered that gonadal mosaicism can never be excluded [28, 29].

The observed partial nullisomy $2 \mathrm{q} 21.1$ to $2 \mathrm{q} 21.3$ in the index patient of case 1, which is most likely due to consanguinity and partial monosomy in both of the parents, also reminds of the possibility that in rare cases a uniparental disomy (UPD) may lead to an MMS with nullisomy or partial tetrasomy [30,31]. For case 1 a $\mathrm{UPD}(2)$ was not excluded, as a biparental origin is here much more likely.

Interestingly, the parental origin of the CNVs showed the same 2:1 (maternal: paternal) ratio (Fig. 3) as e.g. known for the inheritance of small supernumerary marker chromosomes [32]. This normally is explained by higher tolerance of the female gamete producing system towards mistakes in the oocytes, than the testes have towards genetically defective sperm [32-34]. However, the gender ratio of the offspring of cases with parental origin of the CNV of 1:1.8 (female: male) (Fig. 4) is not as easy to explain. Besides a possible bias due to small numbers, it may reflect the fact that CNVs in female are better compensated than in male. Such effects are e.g. observed for patients with 'large CNVs', like in trisomy 13 or 18 [35]. Lion hypotheses and the female mosaic condition of the X-chromosome-inactivation of paternal and maternal copy are discussed to be involved here [36].

Finally, it is known that CNVs seem to be present more or less equally distributed over all human chromosomes [4]; for sure, when looking closer there are hot spots for them, as also reflected by different recombination rates of DNA-stretches with and without $\mathrm{CNVs}$ [15]. The chromosomal origin of the CNVs in this study provides no surprise here (Fig. 5). If the relative high rates of CNVs due to inversions in chromosomes 7 and 17 are meaningful or not, has to be ruled out by future studies. Interestingly for chromosome 17 an inversion polymorphism was reported recently [37].

\section{Conclusions}

Overall, the here suggested new three-color-FISH approach is straightforward and can be universally applied for more comprehensive parental studies of patients with MMS. The detection rate can be increased by $140 \%$ as now also inversions and not only parental deletions and duplications can be detected, which might provide implications for genetic counselling, risk calculation for close relatives, as well as an option for prenatal testing. Still the here applied BACprobesets are only suited for metaphase-FISH; for interphase-FISH distances of 2-5 $\mathrm{Mb}$ between CRP and flanking probes would be indicated [14], and BAC-probes not leading to background and cross-hybridization problems. Nonetheless, the here presented FISH probe set would also be able to detect the elsewhere reported but rare parental insertional balanced translocations as reason of $\mathrm{CNV}$ in the offspring [38].

\section{Additional file}

Additional file 1: Table S1. Besides details listed in Table 1, karyotype of index patient after GTG-banding and array-CGH, and the locus-specific probes used for the molecular cytogenetic study of the parents of the index patient are provided. No detailed clinical data is given, as this is not of interest for this study; all patients were studied due to developmental delay and or/ dysmorphic features. (XLSX $19 \mathrm{~kb}$ )

\section{Abbreviations}

BAC: Bacterial artificial chromosome; CMT1A: Charcot-Marie-Tooth disease type 1A; CNVs: Copy number variants; CR: Critical region; CRP: Critical region probe; FISH: Fluorescence in situ hybridization; GTG: G-bands by trypsin using Giemsa; MMBIR: Microhomology-mediated break-induced replication; 
MMSs: Microdeletion/microduplication syndromes; NAHR: Nonallelic homologous recombination; UPD: Uniparental disomy

\section{Acknowledgements}

We thank for providing cases for this study the following colleagues: Dr. Bartels (Göttingen, Germany), PD Dr. Beger (Bielefeld, Germany), Dr. Coci (Braunschweig and Bochum, Germany), Dr. Belitz (Berlin, Germany), Dr. Dahlum (Ulm, Germany), Dr. Ebner (Regensburg, Germany), Dr. Hehr (Regensburg, Germany), Dr. Huhle (Zwickau, Germany), Dr. Louis (Mannheim, Germany) Dr. Ovens-Räder (Munich, Germany), Dr. Pauli (Göttingen, Germany), Dr. Shoukier (Munich, Germany), Dr. Schulze (Hannover, Germany), Prof. Steinberger (Frankfurt am Main, Germany).

\section{Funding}

Supported in parts by the VDINDE-IT (16KN054624).

\section{Availability of data and materials}

The data sets supporting the conclusions of this article are included within the article.

\section{Authors' contributions}

TL designed the study and drafted the manuscript, supervised the experiments. IS, AK, SS, AD, KW, AW and KM provided the clinical cases and data; $A W, T J$ and RC provided locus specific BAC probes for this study. MZ, SK and KK did the FISH-tests. MAKO and AHA-R did the probe amplification and labelling. All authors edited and approved the manuscript.

\section{Ethics approval and consent to participate}

All procedures followed were in accordance with the ethical standards of the responsible committee on human experimentation (institutional and national). Ethics committee of University Clinic Jena approved the study (2303-05/08).

\section{Consent for publication}

Not applicable.

\section{Competing interests}

The authors declare that they have no competing interests.

\section{Publisher's Note}

Springer Nature remains neutral with regard to jurisdictional claims in published maps and institutional affiliations.

\section{Author details}

'Jena University Hospital, Institute of Human Genetics, Friedrich Schiller University, Postfach D-07740, Jena, Germany. ${ }^{2}$ Center for Ambulant Medicine, Jena University Hospital, Jena, Germany. ${ }^{3}$ Institut für Humangenetik, Universitätsklinikum Essen, Essen, Germany. ${ }^{4}$ Access to Genome, ATG Labs, Athens, Greece. ${ }^{5}$ Institut für Medizinische Genetik und angewandte Genomik, Tübingen, Germany. ${ }^{6}$ Synlab czech s.r.o., synlab genetics s.r.o, Praha, Czech Republic.

Received: 3 January 2018 Accepted: 2 March 2018

Published online: 09 March 2018

\section{References}

1. Liehr T. Benign \& pathological chromosomal imbalances, 1st edition microscopic and submicroscopic copy number variations (CNVs) in genetics and counseling. New York: Academic Press; 2014

2. Weise A, Mrasek K, Klein E, Mulatinho M, Llerena JC Jr, Hardekopf D, et al. Microdeletion and microduplication syndromes. J Histochem Cytochem. 2012;60:346-58

3. Priest JR, Girirajan S, Vu TH, Olson A, Eichler EE, Portman MA. Rare copy number variants in isolated sporadic and syndromic atrioventricular septal defects. Am J Med Genet A. 2012;158A:1279-84.

4. Database of genomic variants. http://dgv.tcag.ca/dgv/app/home. Assessed 18 Dec 2017.

5. Girirajan S, Dennis MY, Baker C, Malig M, Coe BP, Campbell CD, et al. Refinement and discovery of new hotspots of copy-number variation associated with autism spectrum disorder. Am J Hum Genet. 2013;92:221-37.
6. Levinson G, Gutman GA. Slipped-strand mispairing: a major mechanism for DNA sequence evolution. Mol Biol Evol. 1987;4:203-21.

7. Liu P, Canvalho CM, Hastings PJ, Lupski JR. Mechanisms for recurrent and complex human genomic rearrangements. Curr Opin Genet Dev. 2012;22:211-20.

8. Arlt MF, Wilson TE, Glover TW. Replication stress and mechanisms of CNV formation. Curr Opin Genet Dev. 2012;22:204-10.

9. Murakami T, Garcia CA, Reiter LT, Lupski JR. Charcot-Marie-Tooth disease and related inherited neuropathies. Medicine (Baltimore). 1996:75:233-50.

10. Liehr T, Rautenstrauss B, Grehl H, Bathke KD, Ekici A, Rauch A, et al. Mosaicism for the Charcot-Marie-Tooth disease type 1A duplication suggests somatic reversion. Hum Genet. 1996;98:22-8.

11. Mkrtchyan H, Gross M, Hinreiner S, Polytiko A, Manvelyan M, Mrasek K Kosyakova N, Ewers E, Nelle H, Liehr T, Bhatt S, Thoma K, Gebhart E, Wilhelm $\mathrm{S}$, Fahsold R, Volleth M, Weise A. The human genome puzzle - the role of copy number variation in somatic mosaicism. Curr Genomics. 2010 Sep; 11(6):426-31.

12. Girirajan S, Rosenfeld JA, Cooper GM, Antonacci F, Siswara P, Itsara A, et al. A recurrent 16p12.1 microdeletion supports a two-hit model for severe developmental delay. Nat Genet. 2010;42:203-9.

13. Gimelli G, Pujana MA, Patricelli MG, Russo S, Giardino D, Larizza L, et al. Genomic inversions of human chromosome 15q11-q13 in mothers of Angelman syndrome patients with class II (BP2/3) deletions. Hum Mol Genet. 2003;12:849-58.

14. Morris CA, Mervis CB, Osborne LR. Frequency of the 7q11.23 inversion polymorphism in transmitting parents of children with Williams syndrome and in the general population does not differ between North America and Europe. Mol Cytogenet. 2011;4:7.

15. Bhatt SS, Manvelyan M, Moradkhani K, Hunstig F, Mrasek K, Puechberty J, et al. Inverted segment size and the presence of recombination hot spot clusters matter in sperm segregation analysis. Cytogenet Genome Res. 2014; 142:145-9.

16. Jensen M, Kooy RF, Simon TJ, Reyniers E, Girirajan S, Tassone F. A higher rare CNV burden in the genetic background potentially contributes to intellectual disability phenotypes in 22q11.2 deletion syndrome. Eur J Med Genet. https://doi.org/10.1016/j.ejmg.2017.11.016.

17. Tan L, Bi B, Zhao P, Cai X, Wan C, Shao J, et al. Severe congenital microcephaly with $16 p 13.11$ microdeletion combined with NDE1 mutation, a case report and literature review. BMC Med Genet. 2017:18:141.

18. Aguado C, Gayà-Vidal M, Villatoro S, Oliva M, Izquierdo D, Giner-Delgado C, Montalvo V, García-González J, Martínez-Fundichely A, Capilla L, Ruiz-Herrera A, Estivill X, Puig M, Cáceres M. Validation and genotyping of multiple human polymorphic inversions mediated by inverted repeats reveals a high degree of recurrence. PLoS Genet. 2014;10(3):e1004208.

19. Vicente-Salvador D, Puig M, Gayà-Vidal M, Pacheco S, Giner-Delgado C, Noguera I, Izquierdo D, Martínez-Fundichely A, Ruiz-Herrera A, Estivill X, Aguado C, Lucas-Lledó JI, Cáceres M. Detailed analysis of inversions predicted between two human genomes: errors, real polymorphisms, and their origin and population distribution. Hum Mol Genet. 2017;26(3):567-81.

20. Claussen U, Michel S, Mühlig P, Westermann M, Grummt UW, KromeyerHauschild K, et al. Demystifying chromosome preparation and the implications for the concept of chromosome condensation during mitosis. Cytogenet Genome Res. 2002;98:136-46.

21. Weise A, Liehr T. Pre- and postnatal diagnostics and research on peripheral blood, bone marrow chorion, amniocytes, and fibroblasts. In: Liehr T, editor. Fluorescence in situ hybridization (FISH) - application guide. 2nd ed. Berlin: Springer; 2017. p. 171-80.

22. Liehr T. Two- to three-color FISH. In: Liehr T, editor. Fluorescence in situ hybridization (FISH) - application guide. 2nd ed. Berlin: Springer; 2017. p. 227-32.

23. Weise A, Gross M, Hinreiner S, Witthuhn V, Mkrtchyan H, Liehr T. POD-FISH: a new technique for parental origin determination based on copy number variation polymorphism. Methods Mol Biol. 2010;659:291-8.

24. Liehr T. Homemade locus-specific FISH probes: bacterial artificial chromosomes. In: Liehr T, editor. Fluorescence in situ hybridization (FISH) application guide. 2nd ed. Berlin: Springer; 2017. p. 101-6.

25. Manolakos E, Vetro A, Kefalas K, Rapti SM, Louizou E, Garas A, et al. The use of array-CGH in a cohort of Greek children with developmental delay. Mol Cytogenet. 2010;3:22.

26. Demaerel W, Hestand MS, Vergaelen E, Swillen A, López-Sánchez M Pérez-Jurado LA, et al. Nested inversion polymorphisms predispose chromosome 22q11.2 to meiotic rearrangements. Am J Hum Genet. 2017 Oct 5;101(4):616-22. 
27. Fickelscher I, Starke H, Schulze E, Ernst G, Kosyakova N, Mkrtchyan H, MacDermont K, Sebire N, Liehr T. A further case with a small supernumerary marker chromosome (SSMC) derived from chromosome 1-evidence for high variability in mosaicism in different tissues of SSMC carriers. Prenat Diagn. 2007;27:783-5.

28. Kuroda Y, Ohashi I, Saito T, Nagai J, Ida K, Naruto T, Wada T, Kurosawa K. Deletion of UBE3A in brothers with Angelman syndrome at the breakpoint with an inversion at 15q11.2. Am J Med Genet A. 2014;164A:2873-8.

29. Reiss R, Ahern D, Sandstrom M, Wilkins-Haug L. Recurrent enlarged nuchal translucency: first trimester presentation of a familial 15q26 $\rightarrow$ qter deletion. Am J Med Genet A. 2015;167A:612-6.

30. Ting JC, Roberson ED, Miller ND, Lysholm-Bernacchi A, Stephan DA, Capone $\mathrm{GT}$, et al. Visualization of uniparental inheritance, Mendelian inconsistencies, deletions, and parent of origin effects in single nucleotide polymorphism trio data with SNPtrio. Hum Mutat. 2007:28:1225-35.

31. Liehr T. Cytogenetic contribution to uniparental disomy (UPD). Mol Cytogenet. 2010;3:8

32. Liehr T. Familial small supernumerary marker chromosomes are predominantly inherited via the maternal line. Genet Med. 2006;8:459-62.

33. De Braekeleer M, Dao TN. Cytogenetic studies in male infertility: a review. Hum Reprod. 1991;6:245-50.

34. Morel F, Douet-Guilbert N, Le Bris MJ, Herry A, Amice V, Amice J, De Braekeleer M. Meiotic segregation of translocations during male gametogenesis. Int J Androl. 2004;27:200-12

35. Huether CA, Martin RL, Stoppelman SM, D'Souza S, Bishop JK, Torfs CP, Lorey F, May KM, Hanna JS, Baird PA, Kelly JC. Sex ratios in fetuses and liveborn infants with autosomal aneuploidy. Am J Med Genet. 1996;63:492-500.

36. Rinčić M, lourov IY, Liehr T. Thoughts about SLC16A2, TSIX and XIST gene like sites in the human genome and a potential role in cellular chromosome counting. Mol Cytogenet. 2016;9:56.

37. Alves JM, Lima AC, Pais IA, Amir N, Celestino R, Piras G, et al. Reassessing the evolutionary history of the 17q21 inversion polymorphism. Genome Biol Evol. 2015;7:3239-48.

38. Nowakowska BA, de Leeuw N, Ruivenkamp CA, Sikkema-Raddatz B, Crolla $J A$, Thoelen R, Koopmans M, den Hollander N, van Haeringen A, van der Kevie-Kersemaekers AM, Pfundt R, Mieloo H, van Essen T, de Vries BB, Green A, Reardon W, Fryns JP, Vermeesch JR. Parental insertional balanced translocations are an important cause of apparently de novo CNVs in patients with developmental anomalies. Eur J Hum Genet. 2012;20:166-70.

\section{Submit your next manuscript to BioMed Central and we will help you at every step:}

- We accept pre-submission inquiries

- Our selector tool helps you to find the most relevant journal

- We provide round the clock customer support

- Convenient online submission

- Thorough peer review

- Inclusion in PubMed and all major indexing services

- Maximum visibility for your research

Submit your manuscript at www.biomedcentral.com/submit

CBiomed Central 